\title{
Study on Seismic Spectrum and Amplification Effect of Soft Soil in Tianjin New Coastal Area
}

\author{
FU Zhanling ${ }^{1}$, CAO Jingquan ${ }^{1}$, GAO Wuping ${ }^{1}$, YAO Xinqiang ${ }^{1}$ \\ ${ }^{1}$ Eathquake Administration of Tianjin, Tianjin, 300201
}

\begin{abstract}
Tianjin new coastal area has a large area of soft soil with high salinity and high humidity. This kind of foundation has unique spectral characteristics and amplification effect on ground motion, which is a deep factor to increase earthquake damage. Based on the geotechnical data of Tianjin new coastal, we established a simplified calculation model and adopted a nonlinear method to study the seismic spectrum and amplification effect of three typical soft soil foundation with different thickness in Tianjin new coastal area, which real earthquake motion EL-Centro seismic wave passing through, that is in order to provide a basis for the seismic design of engineering structures in this area. The results show that: The soft soil foundation in Tianjin new coastal area has an obvious amplification effect on EL-Centro wave within 8HZ, while the seismic wave greater than $8 \mathrm{HZ}$ rapidly attenuates after filtering through the soft soil, and the amplitude greatly reduced. After the EL-Centro wave passes through the three types of soft soil, the acceleration, velocity and displacement coefficient are always in the state of amplification. The amplification coefficient is the largest in the muddy soil, followed by the muddy clay and the smallest in the silty clay. The softer the soil, the more obvious the amplification effect will be. Except the displacement amplification coefficient does not change much with the increase of soft soil thickness, the acceleration and velocity coefficients increase gradually with the increase of soft soil thickness, and the amplification effect is obvious after reaching the surface.
\end{abstract}

\section{Introduction}

Tianjin is a coastal city, and the Binhai New District within the jurisdiction is of typical soft soil area, featured with extensive distribution of soft soil, large thickness and poor engineering properties. In case of relatively stronger seismic action, relatively large terrain deformation will occur, and then unleash engineering disasters that may result in site damage and infrastructure destroy. For example, Wanghailou Complex in Tianjin New Harbour, completed in 1975, are four-storey residential buildings with the soft clay as foundation, the maximum settlement before Tangshan Earthquake is $47 \mathrm{~cm}$, while the additional settlement in this earthquake is $38 \mathrm{~cm}$, thus resulting in leaning buildings. Due to the $38 \mathrm{~cm}$ land subsidence of deep-well pump house in Hangu Chemical Fertilizer Plant, the well-pipe connections fracture ${ }^{[1]}$. Therefore, conducting effective study on the seismic spectra and amplification characteristics of the soft soil area in this district is of significance to the economic construction of Tianjin.

As early as the end of 1980 s, Liao Zhenpeng, Li Xiaojun [2] et al have conducted research on the equivalent linearization method, and proposed the corresponding calculation procedures. Zhou Kesen (1996)

${ }^{[3]}$ have proceeded the study on the difference scheme and constitutive model of seismic response; Huang Yulong,
Zhou Jintian et al $(2000)^{[4]}$ have studied the influence of soft soil interlayer on seismic response of soft soil site in Hong Kong; Bo Jingshan, Li Xiuling (2003) ${ }^{[5]}$ have researched the influence of different site soil layer construction on ground motion parameters via the equivalent linearization method; Luan Maotian, Lin Gao (1992) ${ }^{[6]}$ have gone into the true-nonlinear analysis method for solving the site seismic response, compiled corresponding calculation procedures, and studied the hyperbolic model of soil mass. Zhang Bingzheng et al ${ }^{[7]}$ have investigated the basic rules of lenticle in single layer on bedrock on ground motion via the finite element method. Zhou Aihong, Yuan Ying ${ }^{[8]}$ et al have adopted the equivalent linearization method to simulate the constitutive model of materials' non-linear increase ANSYS during the secondary development of ANSYS on stochastic seismic response of soil layers. Lu Tao, Zhou Zhenghua et al [9], for estimating the non-linear seismic response in a more reasonable manner, have put forward a time-domain analysis method combining damping ratio and stiffness ratio test curves, and applied this method to non-linear one-dimensional seismic response of Xiangtang array site soil layers, which has been proved to be feasible after comparing the simulated results and actually recorded results. Finally, this method, via numerical modeling, has been proved to be more rational for estimating the seismic response of the ground in case of major earthquake compared to the equivalent 
linearization method. Based on the previous researches, this paper adopts the basic theory of non-linear dynamic analysis method of soil layers based on FLAC ${ }^{3 \mathrm{D}}$, simulates the seismic spectra and amplification effect of EI-Centro seismic waves based on real earthquake ground motion on three typical soft soil foundations with different thickness at the Binhai New District, which can serve as the basis for the aseismic design of engineering structures and earthquake damage alleviation in this area.

\section{Basic Theory of Non-linear Dynamic Analysis Method of Soil Layers based on FLAC ${ }^{3 D}$}

The fully non-linear analysis method adopted by FLAC3D is to solve the equations of all motions by applying the concentrated mass of grid nodes obtained from the true density of the surrounding area based on the explicit difference method. During the calculation, FLAC3D can adjust along with variables, and does no need to iterate for meeting the constitutive relation. The object calculated by FLAC3D is nodes since all forces are imposed on nodes, and then it will solve the motion equation within the time domain, with the form of its motion equation as shown in (1):

$$
\frac{\partial v_{i}^{l}}{\partial t}=\frac{F_{i}^{l}(t)}{m^{l}}
$$

The left side of (1), via numerical difference calculation method, can be:

$$
v_{i}^{l}\left(t+\frac{\Delta t}{2}\right)=v_{i}^{l}\left(t-\frac{\Delta t}{2}\right)+\frac{F_{i}^{l}(t)}{m^{l}} \Delta t
$$

In Equation (2), $F_{i}^{i}(t)$ refers to the unbalanced force component of node in the direction of $i$ and at the time of $\mathrm{t} ;{ }^{v}{ }_{i}^{l}$ refers to be the velocity of node $1 ;{ }^{m}{ }^{l}$ refers to be the concentrated mass of node $1 ; \Delta t$ refers to be the time step increment. (3):

The adopted constitutive relation form is shown in

$$
\sigma_{i j}=M\left(\sigma_{i j}, \dot{e}_{i j}, k\right)
$$

In Equation (3), ${ }^{M}()$ refers to be the constitutive equation form; $k$ refers to be parameters in the history related to time.

In FLAC program, boundary conditions consist of stress and displacement boundary conditions. The displacement boundary condition of given grid nodes can be shown via velocity boundary, while the stress boundary conditions can be available via:

$$
F_{i}=\sigma_{i j}^{b} n_{i} \Delta s
$$

In Equation (4), $n_{i}$ refers to the unit vector at the boundary of outer normal direction; $\Delta s$ refers to the length of stress $\sigma_{i j}^{b}$ on the boundary.

The unit strain increments solved via velocity is as shown in (5):

$$
\Delta e_{i j}=\frac{1}{2}\left(v_{i, j}+v_{j, i}\right) \Delta t
$$

The strain increment obtained from (5) can be fed into (3) to get the stress increment, and the final total stress can be obtained by adding together all stress increments obtained when calculating all time steps.

\section{Site Modelling and Earthquake Ground Motion Processing}

\subsection{Computational model}

The soft soil in Tianjin Binhai New District is mainly distributed in the land area and sea areas within $5 \mathrm{~m}$ in depth, data adopted for land area is engineering investigation, geological survey and other engineering geology borehole data, which can divide the soft soil into mucky soil, mucky clay and mucky silty clay. This paper simplifies the typ The soft soil in Tianjin Binhai New District is mainly distributed in the land area and sea areas within $5 \mathrm{~m}$ in depth, data adopted for land area is engineering investigation, geological survey and other engineering geology borehole data, which can divide the soft soil into mucky soil, mucky clay and mucky silty clay. This paper simplifies the typical soft soil site in Tianjin New District into soft soil site computational model, as shown in Fig. 1, with the bottom being non-soft soil layer with the thickness being $20 \mathrm{~m}$, the upper being soft soil layer with the thickness being $20 \mathrm{~m}$. The lithology of soft soil is mucky soil, mucky clay and mucky silty clay, with the length of the model being $120 \mathrm{~m}$. ical soft soil site in Tianjin New District into soft soil site computational model, as shown in Fig. 1, with the bottom being non-soft soil layer with the thickness being $20 \mathrm{~m}$, the upper being soft soil layer with the thickness being $20 \mathrm{~m}$. The lithology of soft soil is mucky soil, mucky clay and mucky silty clay, with the length of the model being $120 \mathrm{~m}$.

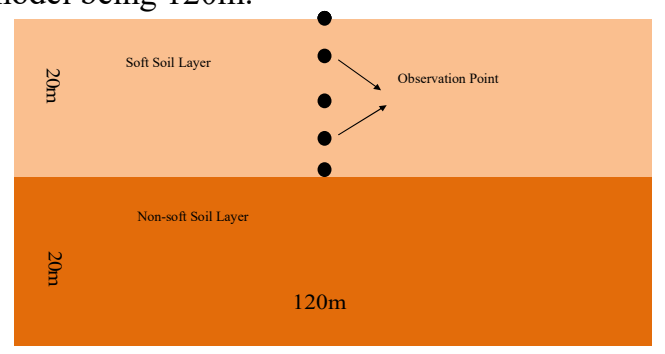

Fig.1 Soft Soil Foundation Model

\subsection{Calculation parameters}

Constitutive models for the soft soil layer and non-soft soil layers are both Mohr - Coulomb models. The model parameters adopted for calculation are as shown in Table 1, with all lithology parameters in Table taken from engineering geological investigation report of certain site and mechanics test on site samples at Binhai New District. Viscous boundary and free field boundary are selected for boundary conditions, with viscous boundary being at the bottom of the model and free field boundary at the residual surroundings of the model. 
Table 1 Computational Model Parameters

\begin{tabular}{ccccccc}
\hline Material type & $\begin{array}{c}\text { Bulk } \\
\text { Modulus } \\
\mathrm{MPa}\end{array}$ & $\begin{array}{c}\text { Shear } \\
\text { Modulus } \\
\mathrm{MPa}\end{array}$ & $\begin{array}{c}\text { Density } \\
\mathrm{Kg} / \mathrm{m} 3\end{array}$ & $\begin{array}{c}\text { Cohesion } \\
\mathrm{KPa}\end{array}$ & $\begin{array}{c}\text { Friction } \\
\text { Angle } \\
\circ\end{array}$ & $\begin{array}{c}\text { Tensile } \\
\text { Strength } \\
\mathrm{MPa}\end{array}$ \\
\hline Non-soft soil layer & 16.42 & 8.25 & 2000 & 32 & 30 & - \\
Mucky Soil & 3.12 & 1.48 & 1770 & 4 & 25 & - \\
Mucky Clay & 3.83 & 1.88 & 1790 & 6 & 27 & - \\
Mucky Silty Clay & 4.34 & 2.12 & 1820 & 8 & 30 & - \\
\hline
\end{tabular}

\subsection{Earthquake ground motion processing}

In this calculation, EI-Centro seismic waves based on real earthquake records (Direction:N-S) have been adopted, and equally scaled to make the maximum acceleration $0.26 \mathrm{~g}$ (equivalent to the seismic load of 7.2 magnitude earthquake), with the early 30 s during the duration of seismic waves selected, and the sampling data interval being $0.02 \mathrm{~s}$. the maximum frequency of earthquake waves has great impact on the number and size of grid cells of the model, since relatively scatter high-frequency earthquake waves will scale up the grid size of model subdivision, thus delaying the computation time, and such high-frequency earthquake waves are temporary short-term effect, without substantial effect on the whole computation, which means that the computation time can be speed up by removing these high-frequency earthquake waves without jeopardizing the accuracy ${ }^{[10]}$. Most energy of EI-Centro seismic waves are distributed within the frequency of $7 \mathrm{HZ}$, and those beyond $7 \mathrm{HZ}$ are only scattering energy, which can be removed. After removal of these scattering energy, this paper carries out the baseline correction on the original seismic waves. Fig. 2(a) shows the El-Centro wave's displacement, velocity, acceleration waveform before and after wave filtering and baseline correction, while Fig. 2(b) shows the El-Centro wave's power spectra before and after filtering and baseline correction.

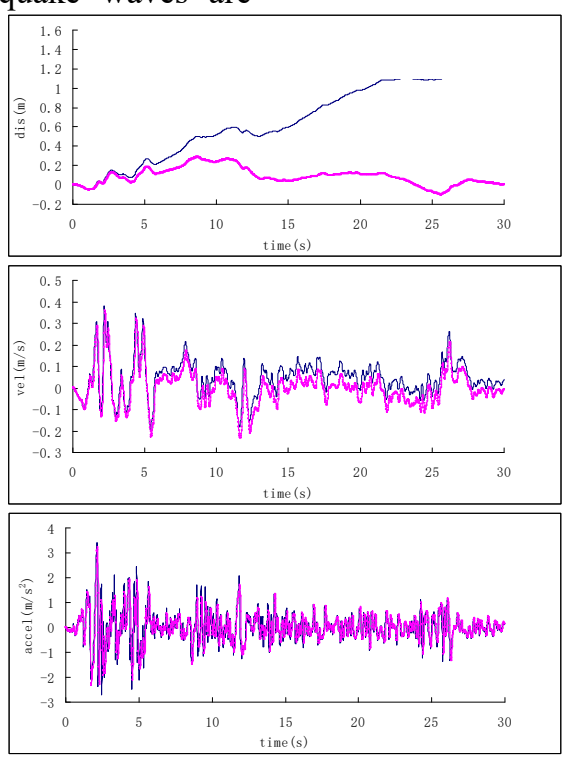

(a)

Fig.2(a) El-Centro Wave's displacement, velocity, acceleration waveform before(black) and after (red)wave filtering and baseline correction
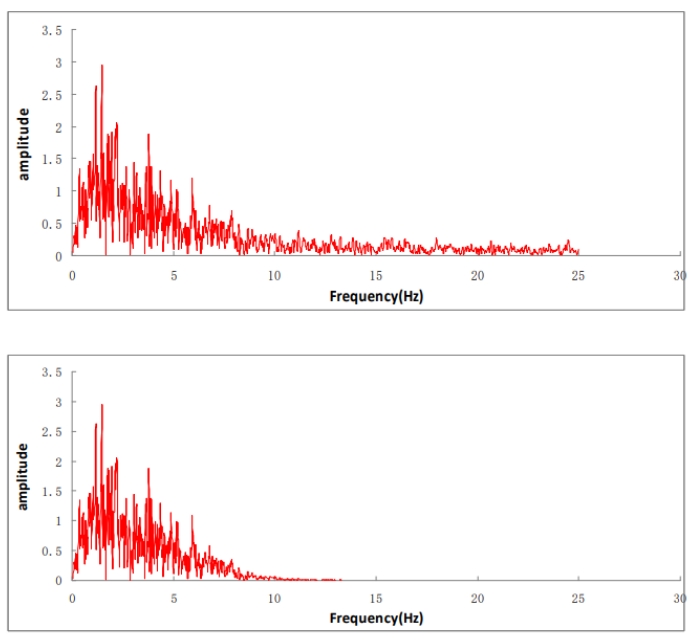

(b)

Fig.2(b) El-Centro Wave's power spectra before(up) and after(down) filtering and baseline correction 


\section{Seismic Spectra and Amplification Effect}

In order to investigate and analyze the seismic spectra and amplification effect of EI-Centro earthquake waves passing through three typical soft soil foundations (mucky soil, mucky clay, mucky silty clay) in Tianjin Binhai New District, with the observation points set at the depth of $0 \mathrm{~m}, 5 \mathrm{~m}, 10 \mathrm{~m}, 15 \mathrm{~m}$ and $20 \mathrm{~m}$ of the soft soil layer in the model shown in Fig. 1.

\subsection{Seismic spectral effect analysis}

Fig. 3 (a) (b) (c) to Fig. 6 (a) (b) (c) show respectively the acceleration and power spectra of earthquake waves amplified after passing through soft soil with three kinds of lithology (mucky soil, mucky clay and mucky silty clay) with different thickness. As we can see from the power spectra of earthquake waves, the soft soil layer can significantly amplify the earthquake waves within $8 \mathrm{HZ}$ frequency, and has the maximum amplification effect on earthquake waves at the frequency of $2 \mathrm{HZ}$. Earthquake waves beyond $8 \mathrm{HZ}$ will decay soon after

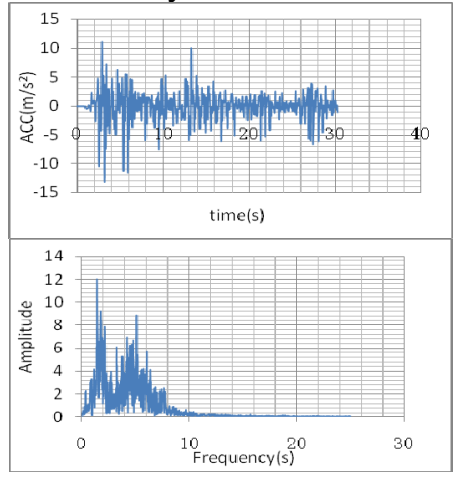

(a)

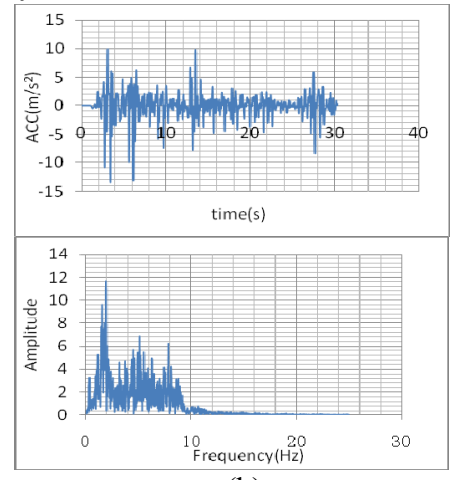

(b) passing through soft soil, with substantial decrease in the amplitude, while earthquake waves within $8 \mathrm{HZ}$ are in the multi-peak form, with various frequency spectrum components. This means that soft soil can inhabit the high-frequency components of earthquake waves, but significantly amplify the low-frequency components, which is identical to the earthquake disaster characteristics of soil soft foundations at home and abroad. Along with the increase of depth, the inhabiting effect on the high-frequency components, as well as the amplification effect on low-frequency components will become increasingly visible.

Fig. 7 (a) (b) (c) show the acceleration and power spectra of El-Centro earthquake waves amplified after passing through non-soft soil layers, and compared with the power spectra of El-Centro earthquake waves in Fig. 2(b), we can see that the non-soft soil layers can substantially amplify the predominant frequency at the frequency of $2 \mathrm{HZ}$, while other frequencies, except for $9 \mathrm{HZ}, 12 \mathrm{HZ}$ and $15 \mathrm{HZ}$ at which non-soft soil layer undergoes minor amplify, decay to different levels after passing through non-soft soil layer, with the power spectra being distinct single-peak form.

Fig3 (a)(b)(c) Acceleration Time History and Power Spectra of Mucky Soil, Mucky Clay and Mucky Silty Clay with the Thickness

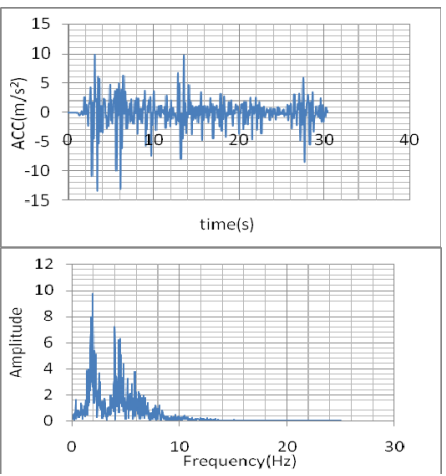

(a)

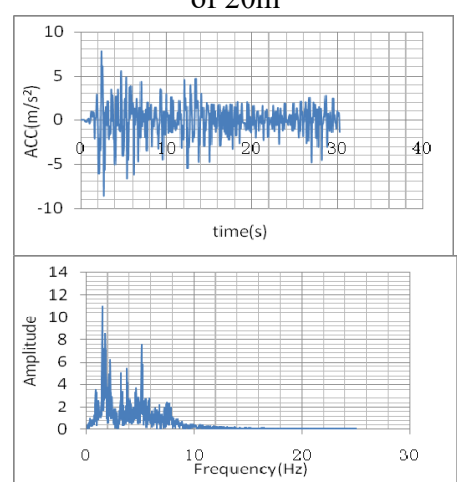

(b)

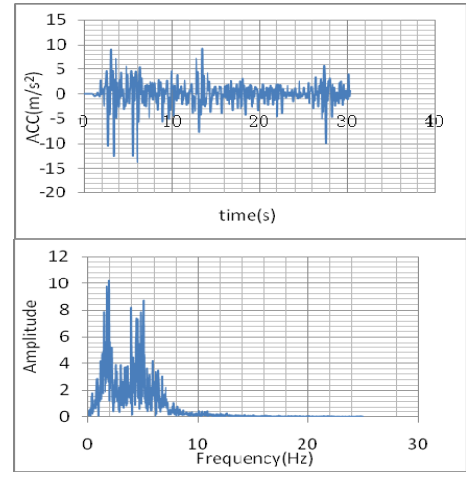

(c)

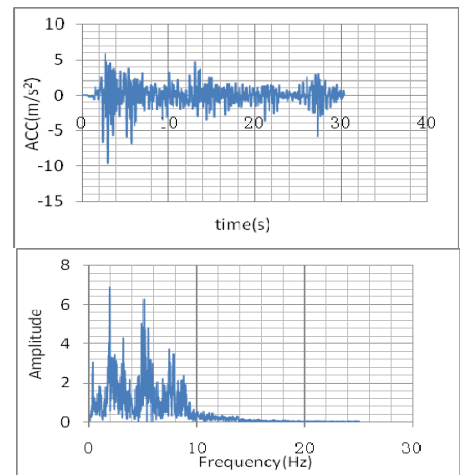

(c)

Fig4 (a)(b)(c) Acceleration Time History and Power Spectra of Mucky Soil, Mucky Clay and Mucky Silty Clay with the Thickness of $15 \mathrm{~m}$
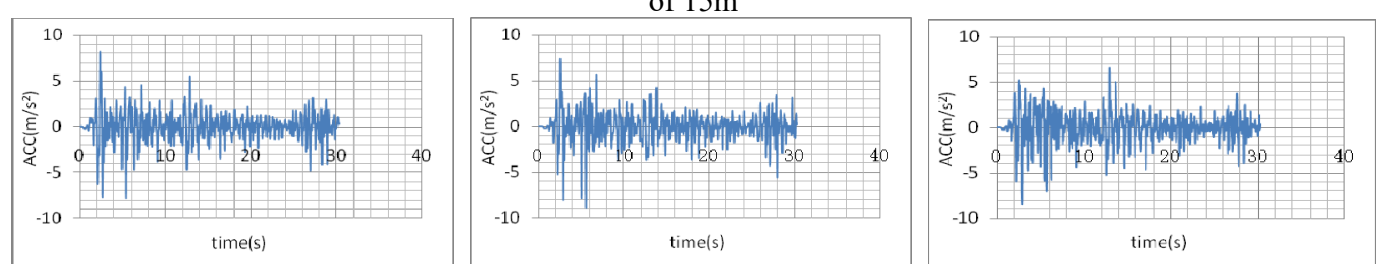


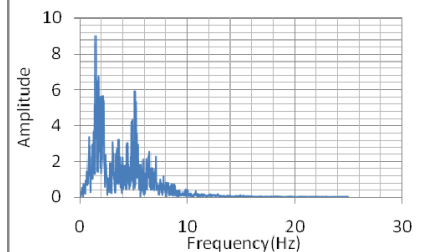

(a)

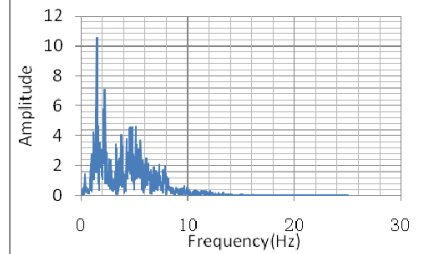

(b)

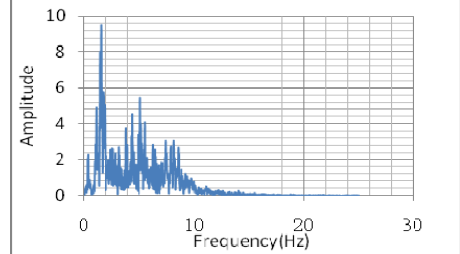

(c)

Fig5 (a)(b)(c) Acceleration Time History and Power Spectra of Mucky Soil, Mucky Clay and Mucky Silty Clay with the Thickness of $10 \mathrm{~m}$

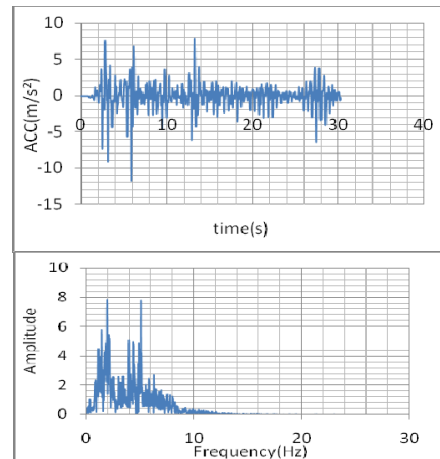

(a)

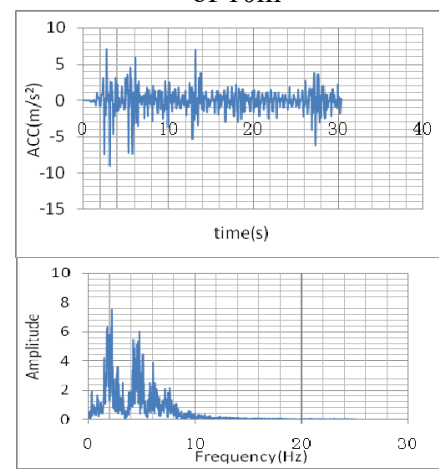

(b)

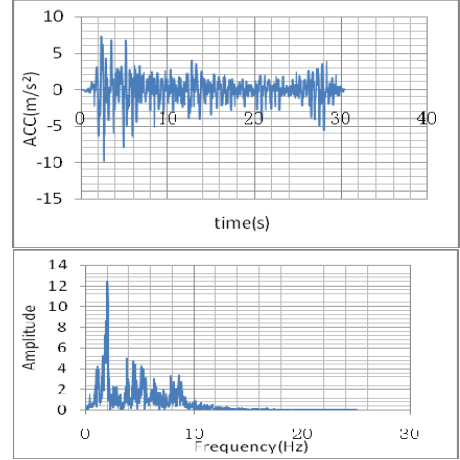

(c)

Fig6 (a)(b)(c) Acceleration Time History and Power Spectra of Mucky Soil, Mucky Clay and Mucky Silty Clay with the Thickness

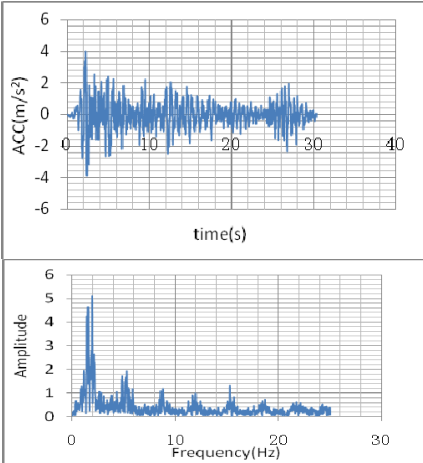

(a) of $5 \mathrm{~m}$

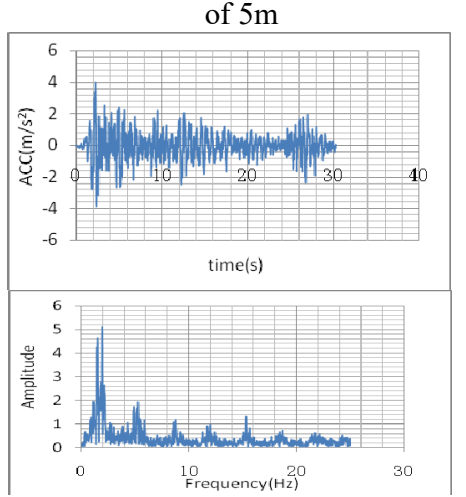

(b)

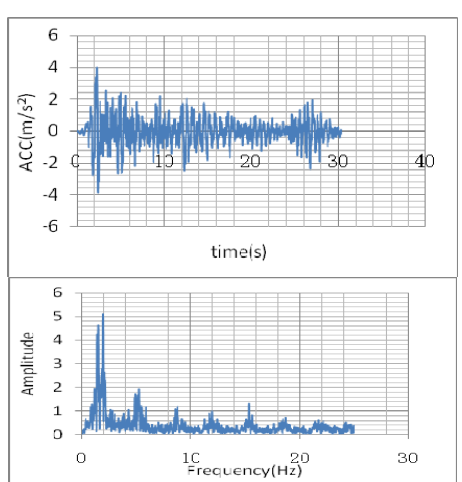

(c)

Fig7 (a)(b)(c) Acceleration Time History and Power Spectra of Mucky Soil, Mucky Clay and Mucky Silty Clay with the Thickness of $0 \mathrm{~m}$

\subsection{Analysis on the amplification effect of earthquake ground motion}

Fig.8 (a) (b) (c)- Fig.11 (a) (b) (c) respectively show the seismic wave velocity and displacement time history curves when the earthquake waves pass through the soft soil with three kinds of lithology (mucky soil, mucky clay, mucky silty clay) at different thickness. Compared with Fig.12 (a) (b) (c) showing the seismic wave velocity and displacement time history curves when EI-Centro earthquake waves pass through the non-soft soil layer, we can see that the the seismic wave velocity when passing through soil soft with three kinds of lithology presents repeated oscillation, and the peak velocity will gradually increase along with the decrease of depth, which is identical to the acceleration amplification effect. The displacement time history also presents the amplification effect, with gradually increased amplitude, with no outstanding change in the amplification effect along with the changes of depth. 

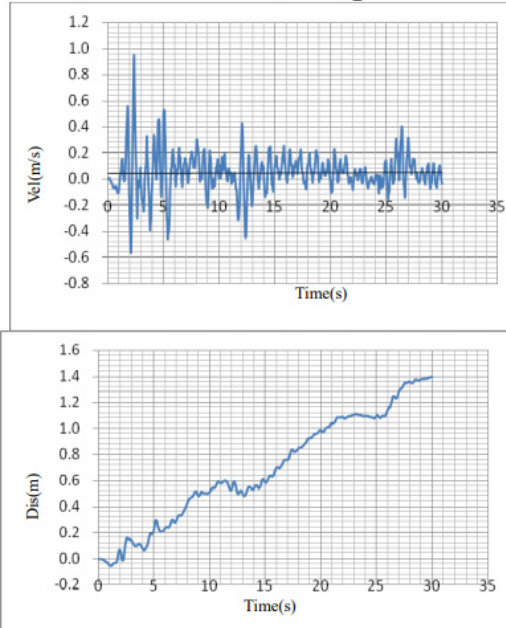

(a)
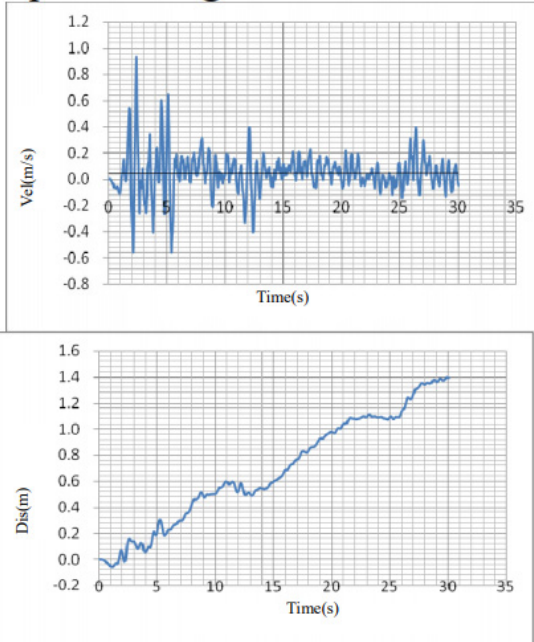

(b)
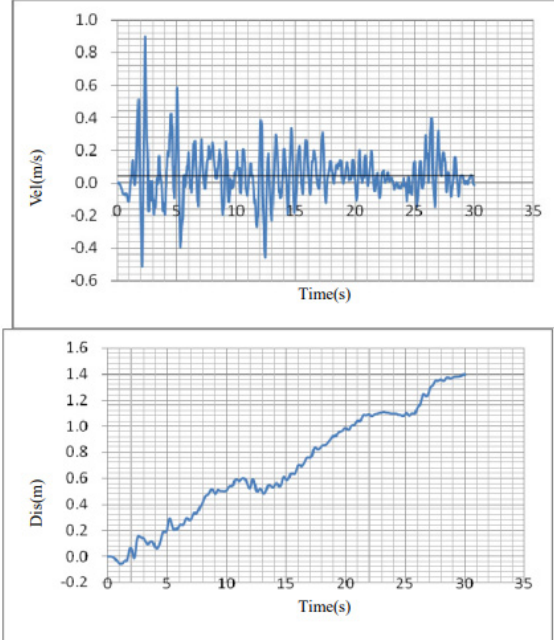

(c)

Fig8 (a)(b)(c) Velocity and Displacement Time History Curves of Mucky Soil, Mucky Clay and Mucky Silty Clay with the Thickness of 20m
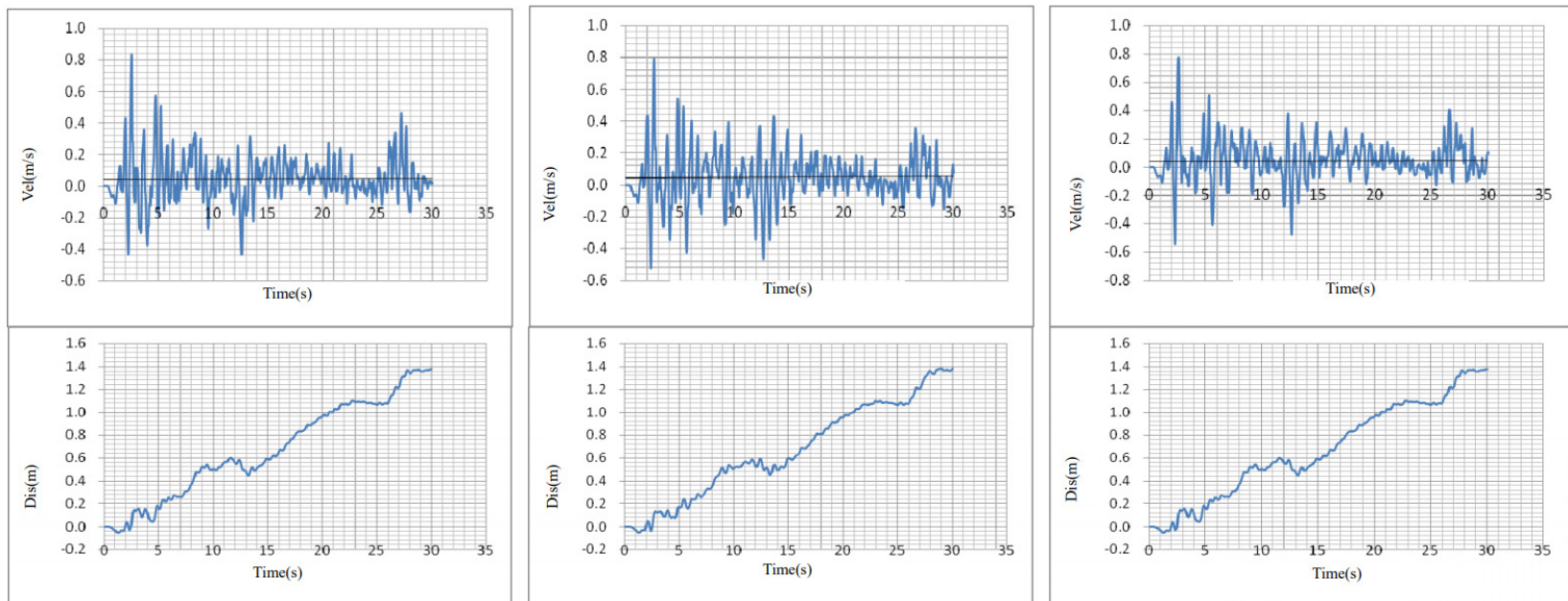

Fig9 (a)(b)(c) Velocity and Displacement Time History Curves of Mucky Soil, Mucky Clay and Mucky Silty Clay with the Thickness of $15 \mathrm{~m}$
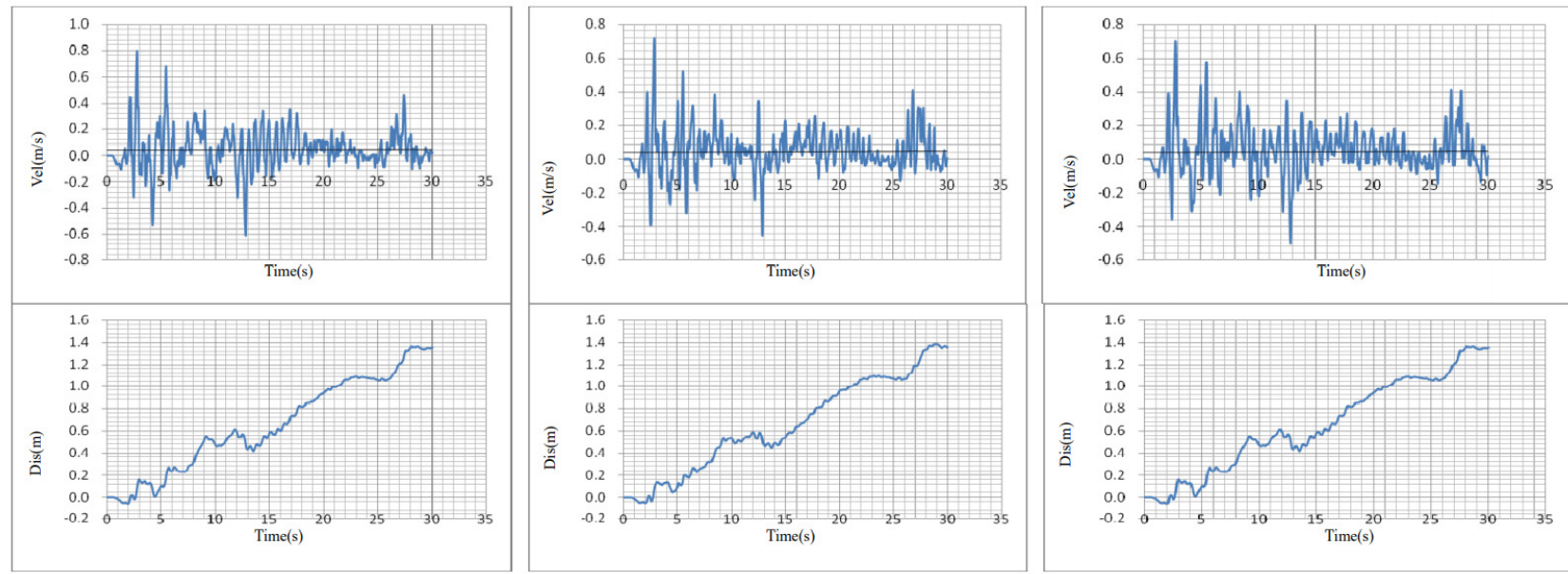

Fig10 (a)(b)(c) Velocity and Displacement Time History Curves of Mucky Soil, Mucky Clay and Mucky Silty Clay with the Thickness of 10m 

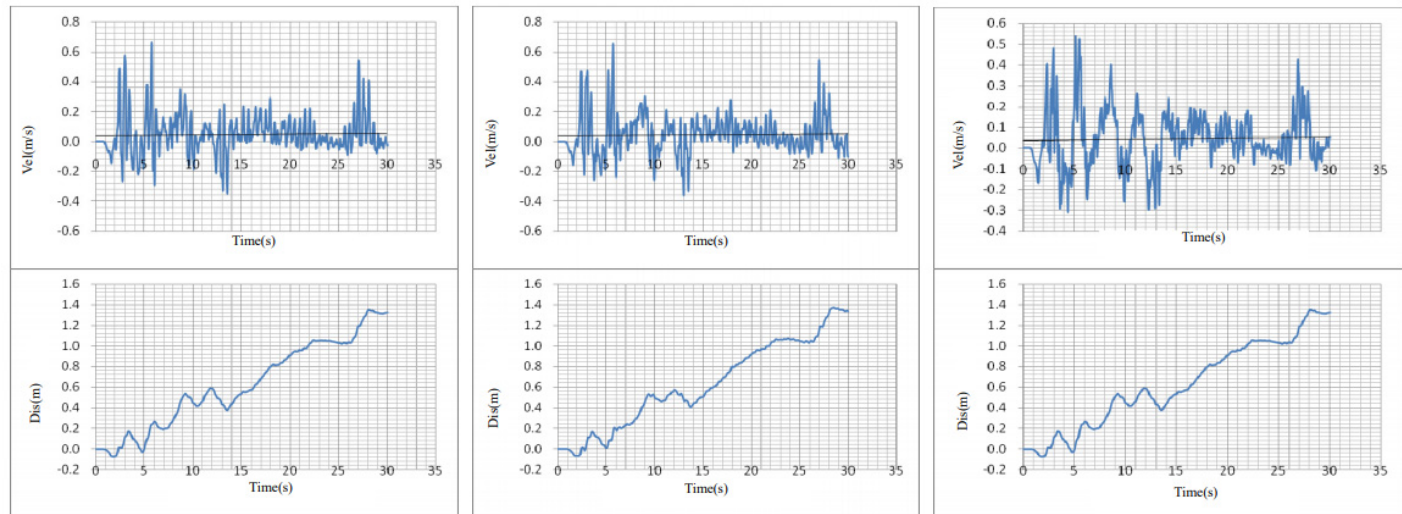

Fig11 (a)(b)(c) Velocity and Displacement Time History Curves of Mucky Soil, Mucky Clay and Mucky Silty Clay with the Thickness of 5m
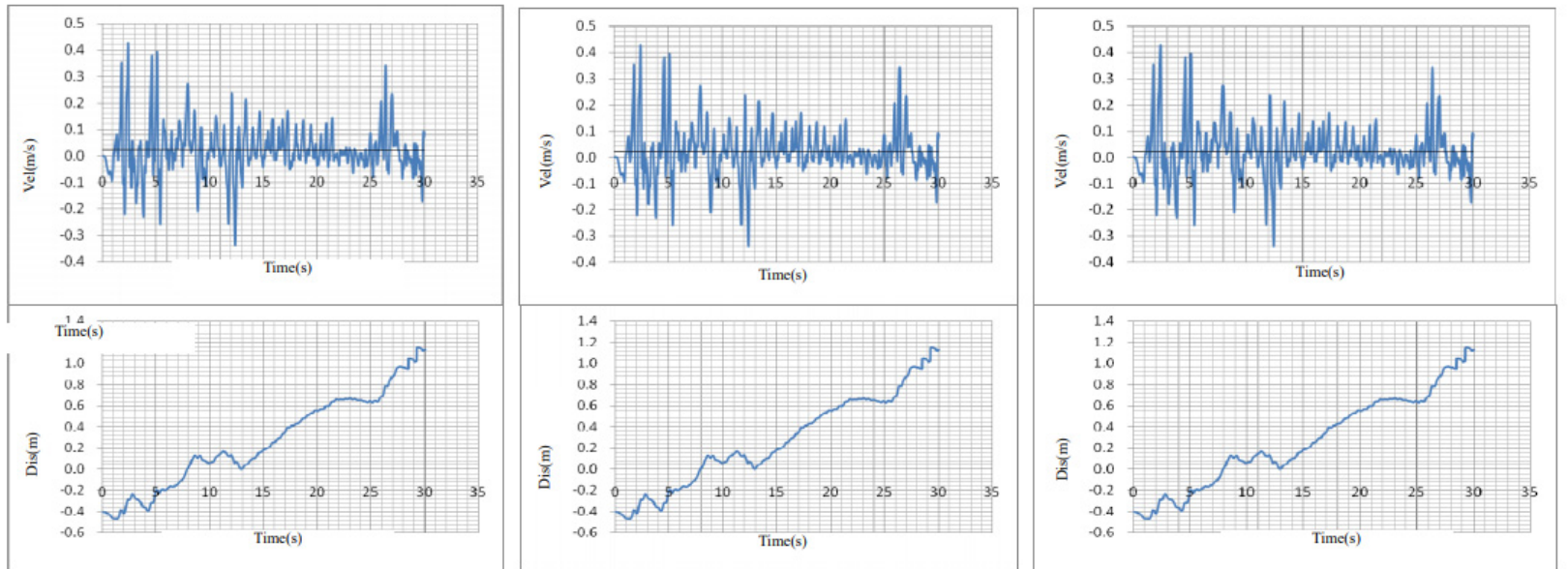

Fig.12 (a)(b)(c) Velocity and Displacement Time History Curves of Mucky Soil, Mucky Clay and Mucky Silty Clay with the Thickness of 0m thickness

Symbols of $\varepsilon, \xi$ and $\eta$ represent displacement same to the principle of displacement amplification amplification coefficient, velocity amplification coefficient and acceleration amplification coefficient respectively. Assume that the maximum displacement of observation point $(E)$ on the surface of soft soil layer in the model during the dynamical computation process is $D_{E}$, and the maximum displacement of node $(C)$ at the surface of non-soft soil layer is $D_{C}$, then the displacement amplification coefficient of this node is $\varepsilon=D_{E} / D_{C}$. Similarly, the definition of velocity amplification coefficient and acceleration amplification coefficient is coefficient. In this way, we can calculate the acceleration, velocity and displacement amplification coefficients of all nodes, as shown in Fig.13 (a) (b) (c), by obtaining the displacement, velocity and acceleration based on the displacement, velocity and acceleration of observation points during the dynamical computation process. The analysis on these three amplification coefficients can be used to reflect the dynamic response rules at Tianjin soft soil areas. 


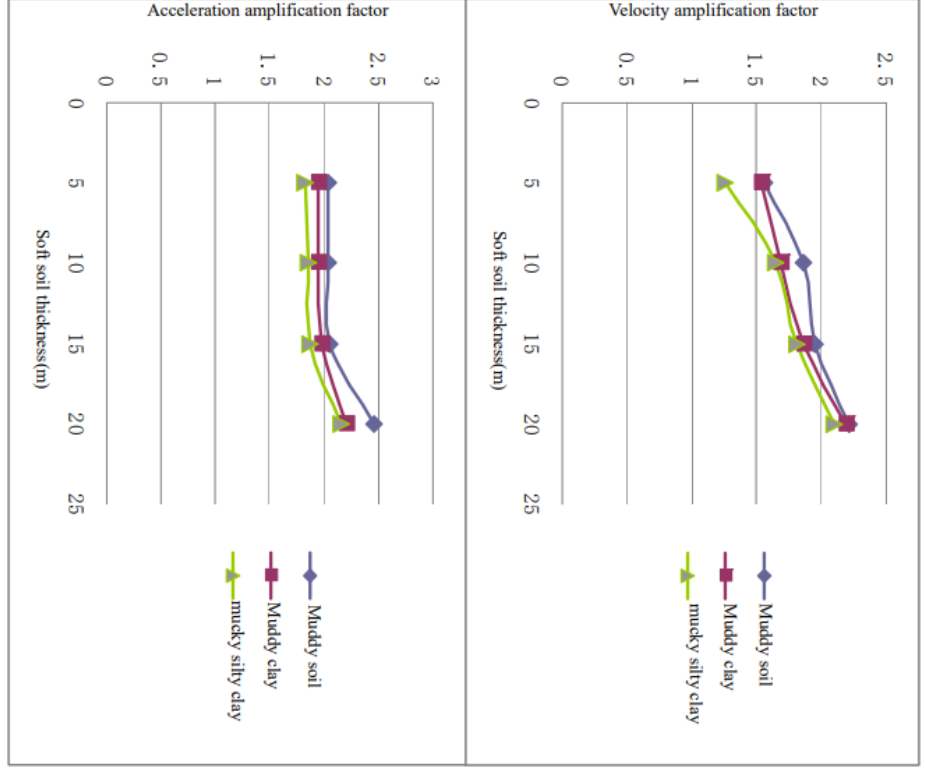

(a) (b)

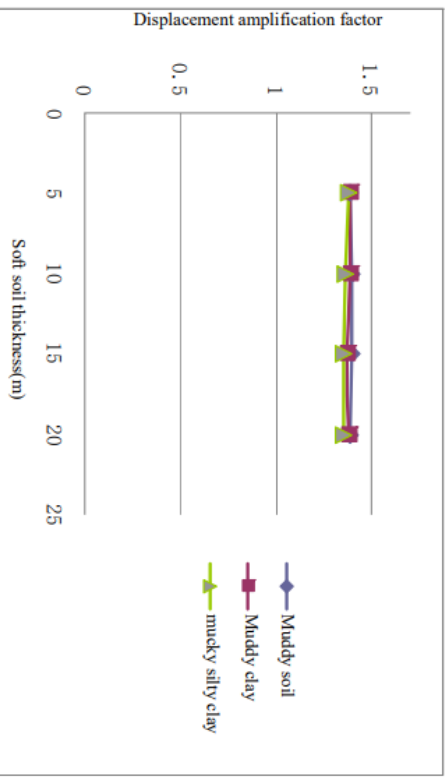

(c)

Fig.13(a)(b)(c) Changes of Acceleration, Velocity and Displacement Amplification Coefficients of Soft Soil Foundations with Three Kinds of Lithology along with Changes of Thickness

As we can see from Fig.13 (a) (b) (c), the acceleration, velocity and displacement of EI-Centro earthquake waves passing through the soft soil layer with three kinds of lithology are constantly amplified, with mucky soilhaving the largest amplification coefficient for all, followed by mucky clay and then mucky silty clay. The acceleration amplification coefficient gradually and slightly increases along with the increase of thickness, but it becomes significant upon reaching to the surface. The velocity amplification coefficient also increases along with the increase of thickness, with the increase amplitude more marked than acceleration amplification coefficient. The displacement amplification coefficient of three kinds of soft soil remains almost the same, being about 1.4 times, and displacement amplification coefficient also increase a little along with the increase of thickness.

According to the above-mentioned statistical results, the peak acceleration, peek velocity and peak displacement of earthquake waves passing the soft soil layer will undergo amplification effect to different levels, this is because when earthquake waves pass across non-soft soil layer and reach to the soft soil layer, the travel velocity will decline, and due to the differences of soil medium, earthquake waves will undergo refraction and reflection at the soil boundary. Such refraction and reflex result in the bounce of earthquake wave energy, trigger the resonance at the low-velocity layer, and multiple times of reflection will extend the duration of earthquake ground motion, this significantly amplifying the amplitude of earthquake ground motion. However, the amplification effect of soft soil with different lithology on the earthquake waves also varies. According to the result, the softer the soil is, the more significant the amplification effect on earthquake waves is. However, these results are only suitable for EL-Centro earthquake waves, and are not necessarily feasible to earthquake waves with other frequency spectrum characteristics.

\section{Conclusion}

This paper builds a simplified computational model based on the representative soft soil (mucky soil, mucky clay and mucky silty clay) in Binhai New District, Tianjin, calculates and analyzes the seismic frequency spectrum and amplification effects of EI-Centro earthquake waves passing non-soft soil layer and soft soil layer by applying the non-linear dynamic analysis method of soil layers based on FLAC ${ }^{3 \mathrm{D}}$. After summing up the acceleration, velocity and displacement records of observation points at different depths, the dynamic response of sites at the typical soft soil layers of Tianjin Binhai New District is shown as below.

(1) For specific EL-Centro earthquake waves, non-soft soil layers can substantially amplify the predominant frequency at the frequency of $2 \mathrm{HZ}$, while other frequencies, except for $9 \mathrm{HZ}, 12 \mathrm{HZ}$ and $15 \mathrm{HZ}$ at which non-soft soil layer undergoes minor amplify, decay to different levels after passing through non-soft soil layer, with the power spectra being distinct single-peak form.

(2) The soft soil layer can significantly amplify the earthquake waves within $8 \mathrm{HZ}$ frequency, while earthquake waves beyond $8 \mathrm{HZ}$ will decay soon after passing through soft soil, with substantial decrease in the amplitude. Earthquake waves within $8 \mathrm{HZ}$ are in the multi-peak form, with various frequency spectrum components. This means that soft soil can inhabit the high-frequency components of El-Centro earthquake waves, but significantly amplify the low-frequency components, which is identical to the earthquake disaster characteristics of soil soft foundations at home and abroad. Along with the increase of depth, the inhabiting effect on the high-frequency components, as well as the 
amplification effect on low-frequency components will become increasingly visible.

(3) The acceleration, velocity and displacement of EI-Centro earthquake waves passing through the soft soil layer with three kinds of lithology are constantly amplified, with mucky soilhaving the largest amplification coefficient for all, followed by mucky clay and then mucky silty clay. The acceleration amplification coefficient gradually and slightly increases along with the increase of thickness, but it becomes significant upon reaching to the surface. The velocity amplification coefficient also increases along with the increase of thickness, with the increase amplitude more marked than acceleration amplification coefficient. The displacement amplification coefficient of three kinds of soft soil remains almost the same, being about 1.4 times, and displacement amplification coefficient also increases a little along with the increase of thickness.

\section{Acknowledgement}

Fund Project: Tianjin Science and Technology Major Project(18ZXAQSF00110); National Natural Science Foundation (41772123)

\section{About the Author}

Fu Zhanling (born in December 1986), male, Han Nationality, born in Tianjin, serve as an engineer, Master Degree Candidate, has been engaged in the research on seismic exploration and earthquake engineering from perspectives of geophysics and geochemistry. E-mail: 375165658@126.com; Tel.: 13516179883. Address: Tianjin Earthquake Administration, No.19, Youyi Road, Tianjin. Postal Code: 300201.

\section{References}

1. Editor-in-chief of Liu Huixian. Earthquake Damage of Tangshan Earthquake, Seismological Press, 1986.

2. Li Xiaojun, Liao Zhenpeng. Visco-elastic-plastic model of soil stress-strain relationship[J]. Earthquake Engineering and Engineering Vibration,vol 3, 1989.

3. Zhou Kesen. $\delta-\theta$ method for nonlinear seismic response analysis of one-dimensional soil layer[J]. Earthquake Engineering and Engineering Vibration, vol 4,1996.

4. Huang Yulong,Zhou Jintian,Guo Xun, Yuan Yifan.Effect of soft clay interlayer on seismic response of Hong Kong soft soil site[J].Journal of Natural Disasters, vol 1,2000.

5. Bo Jingshan,Li Xiuling,Liu Hongshuai.Effect of soil layer structure on peak surface acceleration[J]. Earthquake Engineering and Engineering Vibration,vol 3,2003.

6. Luan Maotian, Lin Gao.One-dimensional nonlinear calculation model of site seismic
response[J].Engineering Mechanics,vol 1,1992.

7. Zhang Bingzheng, Liang Jianwen, Ba Zhenning. The effect of lens on the ground motion in a homogeneous site on bedrock[J]. Journal of Tianjin University, vol 9,2010.

8. Zhou Aihong, Yuan Ying, Zhang Hongru.Analysis of random seismic response of soil layer based on ANSYS secondary development technology[J].Journal of China Coal Society,vol 11,2007 .

9. Lu Tao,Zhou Zhenghua,Huo Jingyan.One-dimensional time domain analysis of nonlinear seismic response of soil layers[J].Rock and Soil Mechanics,vol 8,2008 .

10. Chen Yumin, $\mathrm{Xu}$ Dingping. FLAC/FLAC3D foundation and engineering examples[M]. Beijing: China Water Resources Press, 2009. 